\title{
Impaired Ganglioside Metabolism in Huntington's Disease and Neuroprotective Role of GM1
}

\author{
Vittorio Maglione, Paolo Marchi, Alba Di Pardo, Susanne Lingrell, Melanie Horkey, Emily Tidmarsh, \\ and Simonetta Sipione \\ Department of Pharmacology, University of Alberta, Edmonton, Alberta T6G 2H7, Canada
}

Huntington's disease (HD) is a neurodegenerative disorder caused by the expansion of a polyglutamine stretch in the protein huntingtin (Htt). HD neurons are dysfunctional at multiple levels and have increased susceptibility to stress and apoptotic stimuli. We have discovered that synthesis of the ganglioside GM1 is reduced in fibroblasts from HD patients and in cell and animal models of HD, and that decreased GM1 levels contribute to heighten HD cell susceptibility to apoptosis. The apoptotic susceptibility is recapitulated through inhibition of ganglioside synthesis in wild-type striatal cells, suggesting that decreased GM1 levels might be one of the key events leading to HD pathogenesis and progression. Administration of GM1 restores ganglioside levels in HD cells and promotes activation of AKT and phosphorylation of mutant $\mathrm{Htt}$, leading to decreased mutant $\mathrm{Htt}$ toxicity and increased survival of $\mathrm{HD}$ cells. Our data identify GM1 as a potential treatment for $\mathrm{HD}$.

\section{Introduction}

Huntington's disease (HD), the most common inherited neurodegenerative disorder, is characterized by chorea and progressive motor, psychiatric, and cognitive decline. The disease is caused by expansion ( $>36$ glutamines) of a polyglutamine stretch (polyQ) in the N-terminal region of huntingtin (Htt), a ubiquitous protein with still unclear function (Walker, 2007). Expansion of the polyQ stretch endows mutant Htt ( $\mathrm{mHtt}$ ) with toxic properties and results in the development a broad array of cell dysfunctions, including transcriptional dysregulation, mitochondrial metabolism aberrations, and impaired cell signaling, axonal transport, and synaptic activity (Imarisio et al., 2008). In addition, neurons bearing the mutation are thought to be in an abnormal homeostatic state characterized by lower thresholds for the activation of cell death (Clarke et al., 2000). This might be, at least in part, the result of impaired cell signaling and overall imbalance between activation of prosurvival and apoptotic pathways. In fact, the p53 pathway, an important player in the cell response to stress, is upregulated in HD neurons (Sipione et al., 2002; Bae et al., 2005). On the other hand, activation of the prosurvival PI3K/AKT pathway is impaired in HD models and patients' lymphocytes (Humbert et al., 2002; Song et al., 2002; Colin et al., 2005). Generation of toxic N-terminal fragments of $\mathrm{mHtt}$ by proteolytic cleavage of the full-length protein represents a critical step in HD pathogenesis (Imarisio et al., 2008), a step that

\footnotetext{
Received Dec. 22, 2009; accepted Feb. 3, 2010.

This work was supported by the Huntington Society of Canada, the Canadian Institutes for Medical Research, Canada Foundation for Innovation, and the Alberta Heritage Foundation for Medical Research (AHFMR). Dr. Sipione is an AHFMR Scholar and Canada Research Chair. Dr. Maglione is supported by an AHFMR fellowship. We are gratefu to Dr. R. W. Ledeen (New Jersey Medical School, Newark, NJ) for the generous gift of LIGA-20. We thank Dr. Elena Posse de Chaves (University of Alberta, Edmonton, Alberta, Canada) for critical reading of this manuscript.

Correspondence should be addressed to Simonetta Sipione, Department of Pharmacology, University of Alberta,

9-21 Medical Sciences Building, Edmonton, Alberta T6G 2H7, Canada. E-mail: ssipione@ualberta.ca.

DOI:10.1523/JNEUROSCI.6348-09.2010

Copyright $\odot 2010$ the authors $\quad 0270-6474 / 10 / 304072-09 \$ 15.00 / 0$
}

can be modulated by phosphorylation of $\mathrm{mHtt}$ by AKT (Humbert et al., 2002; Warby et al., 2009) and other kinases (Imarisio et al., 2008).

Here, we describe a new dysfunction in HD, the dysregulation of ganglioside synthesis, which affects cell signaling and HD cell susceptibility to apoptosis. Gangliosides are sialic acid-containing glycosphingolipids that are particularly enriched in the brain. They are major components of membrane microdomains known as "lipid rafts" and play an important role in cell signaling (Sonnino et al., 2007) and cell-cell interaction (Hakomori Si, 2002). The importance of gangliosides in the CNS is underscored by the fact that loss-of-function mutation in the gene encoding GM3 synthase, a key enzyme in the ganglioside biosynthetic pathway, leads to a severe infantile neurodegenerative disorder characterized by progressive brain atrophy, epilepsy and chorea (Simpson et al., 2004), symptoms that are also common to the juvenile form of HD (Squitieri et al., 2006). Lack of complex gangliosides (GM2, GM1, GD1a, and GT1a) in GM2/GD2 synthase null mice is also accompanied by neurodegeneration and motor symptoms (Chiavegatto et al., 2000) resembling those of YAC128 mice, one of the best-characterized models of HD (Slow et al., 2003).

In this study, we demonstrate that reduced synthesis of GM1 - and potentially also other gangliosides-occurs in several models of HD and in fibroblasts from HD patients, contributing to increased susceptibility of HD cells to apoptosis. Administration of GM1 to HD cells restores normal cellular levels of the ganglioside and drastically increases survival. We also show that GM1-mediated neuroprotection involves two crucial modulators of mHtt toxicity: the AKT pathway and Htt phosphorylation state.

\section{Materials and Methods}

Animal and cell models. YAC128 mice were purchased from the Jackson Laboratories. Female YAC128 mice were crossed with male FVB/N wildtype mice for colony maintenance. All procedures on animals were ap- 
A
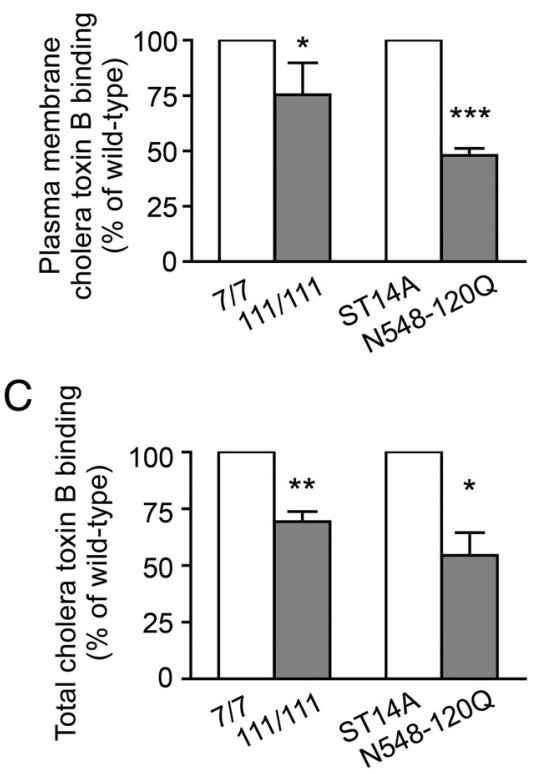

D
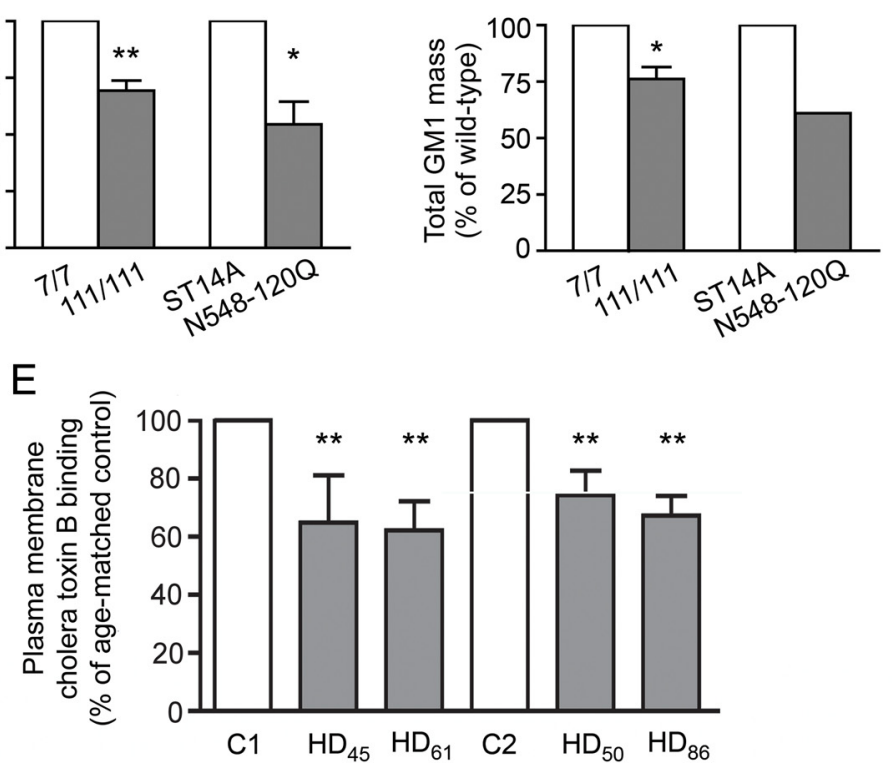

Figure 1. Levels of the ganglioside GM1 are reduced in HD cells. A, Quantitation of plasma membrane GM1 by Alexa488conjugated cholera toxin B labeling and FACS analysis. Data represent the mean \pm SD of three to five independent experiments, each performed in triplicate. $\boldsymbol{B}$, Confocal microscopy images of parental (ST14A) and mHtt-expressing cells (N548-120Q) labeled with Alexa594-conjugated cholera toxin $B$ at $4^{\circ} \mathrm{C}$ to visualize plasma membrane GM1. Images are three-dimensional reconstructions of confocal Z-stacks. C, Total (plasma membrane plus intracellular) GM1 measured by cholera toxin B labeling of fixed and permeabilized cells. Data are the mean \pm SD of three experiments. $D$, Total GM1 measured in cell gangliosides extracts separated and visualized on TLC as described in Materials and Methods. Because of the large number of cells required, this confirmatory experiment was performed only once in ST14A and N548-120Q cells, and therefore SDs were not included in the graph. E, Plasma membrane GM1 levels in human fibroblasts from HD patients and normal subjects. HD fibroblasts were compared with agematched controls at the same passage number ( $(1$ and $(2)$. Subscripts represent the number of CAG repeats in the HD gene of the affected individuals. Additional information on human fibroblast lines is provided in supplemental Table 1 (available at www. jneurosci.org as supplemental material). Data are the mean $\pm S D$ of three experiments performed on cells at three different passages in culture. 7/7, STHdh ${ }^{7 / 7} ; 111 / 111, \mathrm{STHdh}^{111 / 111} ;{ }^{*} p<0.05 ;{ }^{* *} p<0.001$; ${ }^{* * *} p<0.0001$.

proved by the University of Alberta's Animal Care and Use Committee and were in accordance with the guidelines of the Canadian Council on Animal Care.

Conditionally immortalized rat striatal ST14A cells and ST14A cells expressing an N-terminal fragment of $\mathrm{mHtt}$ containing 120 glutamines (N548-120Q) were kindly provided by Dr. E. Cattaneo (University of Milan, Milan, Italy) and maintained in culture at the permissive temperature $\left(33^{\circ} \mathrm{C}\right)$ as previously reported (Rigamonti et al., 2000). Conditionally immortalized mouse striatal knock-in cells expressing endogenous levels of wild-type $\left(\mathrm{STH} d h^{7 / 7}\right)$ or $\mathrm{mHtt}\left(\mathrm{STH} d h^{111 / 111}\right)$ were a gift from Dr. M.E. MacDonald (Massachusetts General Hospital, Boston, MA) and were maintained as previously described (Trettel et al., 2000). Human skin fibroblasts isolated from HD patients were purchased from the Coriell Cell Repositories (Coriell Institute for Medical Research, Camden, $\mathrm{NJ}$ ) and grown in MEM (Invitrogen) supplemented with 15\% FBS, $2 \mathrm{~mm}$ L-glutamine, $100 \mathrm{U} / \mathrm{ml}$ penicillin, $100 \mu \mathrm{g} / \mathrm{ml}$ streptomycin, and $0.11 \mathrm{~g} / \mathrm{L}$ sodium pyruvate (Invitrogen).
Primary cultures of neurons and astrocytes. Cultures of primary cortical and striatal neurons were prepared from newborn mice $(\mathrm{P} 0)$. Briefly, the brain was dissected, and selected regions were minced and digested with 1 $\mathrm{mg} / \mathrm{ml}$ papain for $10 \mathrm{~min}$ at $37^{\circ} \mathrm{C}$. DNase was added to the digestion mix in the last $5 \mathrm{~min}$ of incubation. Cells were centrifuged at $200 \times g$ for $1 \mathrm{~min}$, resuspended in Neurobasal-A medium (Invitrogen) supplemented with 1\% B27 (Invitrogen), and gently dissociated by pipetting up and down. Neurons were plated onto poly-D-lysine-coated wells at a density of $0.1 \times$ $10^{6}$ cells $/ \mathrm{cm}^{2}$ and used for experiments at 9-11 d in vitro. Astrocytes were isolated from 2-d-old (P2) mice and maintained in culture for $20 \mathrm{~d}$ as previously described (Karten et al., 2005).

Confocal microscopy of cholera toxin B surface binding. Cells were seeded onto glass coverslips coated with $50 \mu \mathrm{g} / \mathrm{ml}$ poly-L-lysine. The day after, cells were fixed in $4 \%$ paraformaldehyde at room temperature (r.t.) for $10 \mathrm{~min}$ and then incubated in $1.5 \mathrm{mg} / \mathrm{ml}$ glycine in PBS for 10 min at r.t., followed by $10 \mu \mathrm{g} / \mathrm{ml}$ Alexa594conjugated cholera toxin B (Invitrogen) in $\mathrm{PBS} / 0.1 \% \mathrm{BSA}$ for $20 \mathrm{~min}$ at $4^{\circ} \mathrm{C}$. Slides were analyzed with an LSM510 laser scanning confocal microscope mounted on a Zeiss Axiovert 100M microscope. Images of wild-type and HD cells were acquired using the same confocal settings. Z-stack images were compressed into a single projection image.

Determination of plasma membrane and total GM1 content by flow cytometry. Plasma membrane and total GM1 levels were measured by cholera toxin B subunit binding (Holmgren et al., 1975) and fluorescence-activated cell sorting (FACS) analysis. For plasma membrane binding, cells were trypsinized, washed in icecold HBSS (Invitrogen), and labeled with 2 $\mu \mathrm{g} / \mathrm{ml}$ Alexa488-conjugated cholera toxin B (Invitrogen) in $\mathrm{PBS} / 0.1 \%$ fat-free BSA for 5 $\min$ at $4^{\circ} \mathrm{C}$. Under these conditions, intracellular transport and internalization of cholera toxin are inhibited, and therefore only the GM1 present at the plasma membrane is labeled. After washing, cells were fixed with $2 \%$ paraformaldehyde and stored at $+4^{\circ} \mathrm{C}$ until FACS analysis was performed. For analysis of total GM1 content, cells were fixed in $2 \%$ paraformaldehyde for $30 \mathrm{~min}$ and incubated for $1 \mathrm{~h}$ at room temperature in $4 \mu \mathrm{g} / \mathrm{ml} \mathrm{Alexa488-}$ conjugated cholera toxin B in PBS containing 0.3\% saponin and 1\% BSA. FACS analysis was performed using a FACSCalibur flow cytometer and CellQuest software (BD Biosciences).

Determination of total GM1 content by dot-blotting. Cells were lysed in Tris-buffered saline (TBS) containing $0.1 \%$ Tween 20 (TBS-T) and a protease inhibitors mixture (1:100, Sigma-Aldrich), and homogenized by repeated passages through a $1 \mathrm{ml}$ syringe with a 26 gauge needle. Two microliters of cell lysate (100 ng of proteins) were spotted onto TransBlot Transfer Medium nitrocellulose membrane (Bio-Rad Laboratories). Nonspecific binding to the membrane was blocked with $5 \%$ milk in TBS-T for $1 \mathrm{~h}$ at r.t. The membrane then was incubated for $30 \mathrm{~min}$ at r.t. in $400 \mathrm{ng} / \mathrm{ml} \mathrm{HRP-conjugated} \mathrm{cholera} \mathrm{toxin} \mathrm{B} \mathrm{subunit} \mathrm{(Invitrogen)} \mathrm{in}$ $5 \%$ milk/TBS-T. Visualization was performed by ECL Plus (GE Healthcare).

Analysis of gangliosides by thin-layer chromatography. Tissue (striatum and cortex) or cultured cells were homogenized in $10 \mathrm{~mm}$ Tris- $\mathrm{HCl}, \mathrm{pH}$ 
7.4, containing $1 \mathrm{~mm}$ DTT. Total lipids (TLs) were extracted from tissue ( $1 \mathrm{mg}$ of protein) or cells $\left(10 \mathrm{mg}\right.$ of protein) in $\mathrm{CHCl}_{3} / \mathrm{CH}_{3} \mathrm{OH} /$ $\mathrm{H}_{2} \mathrm{O}$ (4:8:3), and particulate material was removed by centrifugation at $750 \times g$ at $4^{\circ} \mathrm{C}$ for $10 \mathrm{~min}$. Gangliosides were isolated from TL extracts essentially as previously described (Ladisch and Gillard, 1985). Briefly, the TL extract was dried under a stream of nitrogen and the residue was dissolved in di-isopropyl ether/ buthanol $/ 50 \mathrm{~mm} \mathrm{NaCl}(3: 2: 2.5 \mathrm{v} / \mathrm{v} / \mathrm{v})$. Gangliosides partitioning into the lower aqueous phase were recovered and dried under nitrogen. The residue was dissolved in sterile water and desalted by gel filtration using a Sephadex G-50 (Sigma-Aldrich) column. The eluate was collected in $0.5 \mathrm{ml}$ fractions, and the presence of gangliosides in the fraction was confirmed by reading the adsorbance of each fraction at 206 $\mathrm{nm}$. Fractions containing gangliosides (fractions 5-10) were pooled, lyophilized, and redissolved in $\mathrm{CH}_{3} \mathrm{OH} / \mathrm{CHCl}_{3}(1: 1 \mathrm{v} / \mathrm{v})$. Gangliosides were then spotted onto TLC plates (EMD Chemicals) and separated with $\mathrm{CHCl}_{3} / \mathrm{CH}_{3} \mathrm{OH} /$ $0.25 \% \mathrm{KCl}(5: 4: 1 \mathrm{v} / \mathrm{v} / \mathrm{v})$. Ganglioside bands were revealed by reaction with resorcinol $\left(0.2 \%\right.$ resorcinol, $\left.80 \% \mathrm{HCl}, 0.25 \mathrm{~mm} \mathrm{CuSO}_{4}\right)$ in an oven at $120^{\circ} \mathrm{C}$ for $15 \mathrm{~min}$ and identified by comparison with a standard ganglioside mix (Matreya). Relative quantitation of ganglioside bands was performed by densitometric analysis using Quantity One software (BioRad Laboratories).

RNA extraction and real-time PCR analysis of gene expression. Total RNA was extracted using RNeasy kit (Qiagen) according to the manufacturer's instructions. For analysis of gene expression in cell lines and human fibroblasts, total RNA was prepared from cells at three consecutive passages in culture. All samples were subjected to in-column treatment with DNaseI (Qiagen) to eliminate genomic DNA contamination. One microgram of total RNA was reverse transcribed using Superscript II reverse transcriptase (Invitrogen) and oligo- $\mathrm{d}(\mathrm{T})$ primer, and the resulting cDNAs were amplified using Power SYBR Green PCR Master Mix (Applied Biosystems) following the manufacturers' instructions. Genespecific primers were designed using Primer Express 3.0 software (Applied Biosystems). Primer sequences are listed in supplemental Table 2 (available at www.jneurosci.org as supplemental material). Quantitative PCR analysis was performed on a StepOnePlus instrument (Applied Biosystems), by comparison with a standard curve generated by cDNA serial dilutions. The level of each mRNA was normalized to that of cyclophilin A. PCR cycling parameters were as follows: $50^{\circ} \mathrm{C}$ for $2 \mathrm{~min}, 95^{\circ} \mathrm{C}$ for $5 \mathrm{~min}$, followed by 40 cycles of $95^{\circ} \mathrm{C}$ for $20 \mathrm{~s}, 60^{\circ} \mathrm{C}$ for $1 \mathrm{~min}$, and $72^{\circ} \mathrm{C}$ for $40 \mathrm{~s}$.

Analysis of apoptosis and treatments with ganglioside GM1, LIGA-20, and inhibitors. To induce apoptosis, immortalized cells were incubated at $39^{\circ} \mathrm{C}$ (Rigamonti et al., 2000) in serum-free medium for the indicated time. At the end of each treatment, cells were collected and incubated with phycoerythrin-conjugated annexin $\mathrm{V}$ (BD Biosciences) according to the manufacturer's instructions. For the simultaneous detection of active caspase- 3 and annexin $\mathrm{V}$ binding, cells were first labeled with annexin $\mathrm{V}$ as indicated above, then fixed, permeabilized with $0.3 \%$ saponin, and incubated for $1 \mathrm{~h}$ with FITC-conjugated anti-active caspase-3 antibody (1:200, BD Biosciences). FACS analysis was performed as indicated above.

GM1 (Alexis) and LIGA-20 (kindly donated by Dr. R. W. Ledeen, New Jersey Medical School, Newark, NJ) at the indicated concentrations were added to the cells in serum-free medium at the time when cells were shifted at $39^{\circ} \mathrm{C}$ to induce apoptosis. To inhibit ganglioside synthesis, wild-type cells were incubated for $3 \mathrm{~d}$ in medium containing $10 \mu \mathrm{M}$ 1-phenyl-2-palmitoylamino-3-morpholino-1-propanol (PPMP, Matreya). Cells were then washed twice with PBS and incubated for $12 \mathrm{~h}$ at $39^{\circ} \mathrm{C}$ in serum-free medium to induce apoptosis. K252a (200 nM, Calbiochem) was used to inhibit TrK receptor-mediated signaling. Triciribine (TCN, 1 $\mu \mathrm{M}$; BIOMOL International) was used to inhibit AKT activation. Both
B

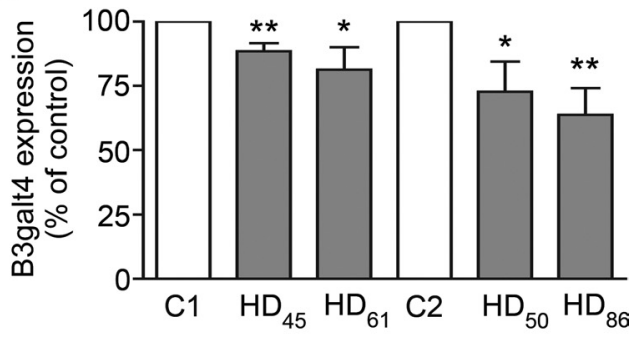

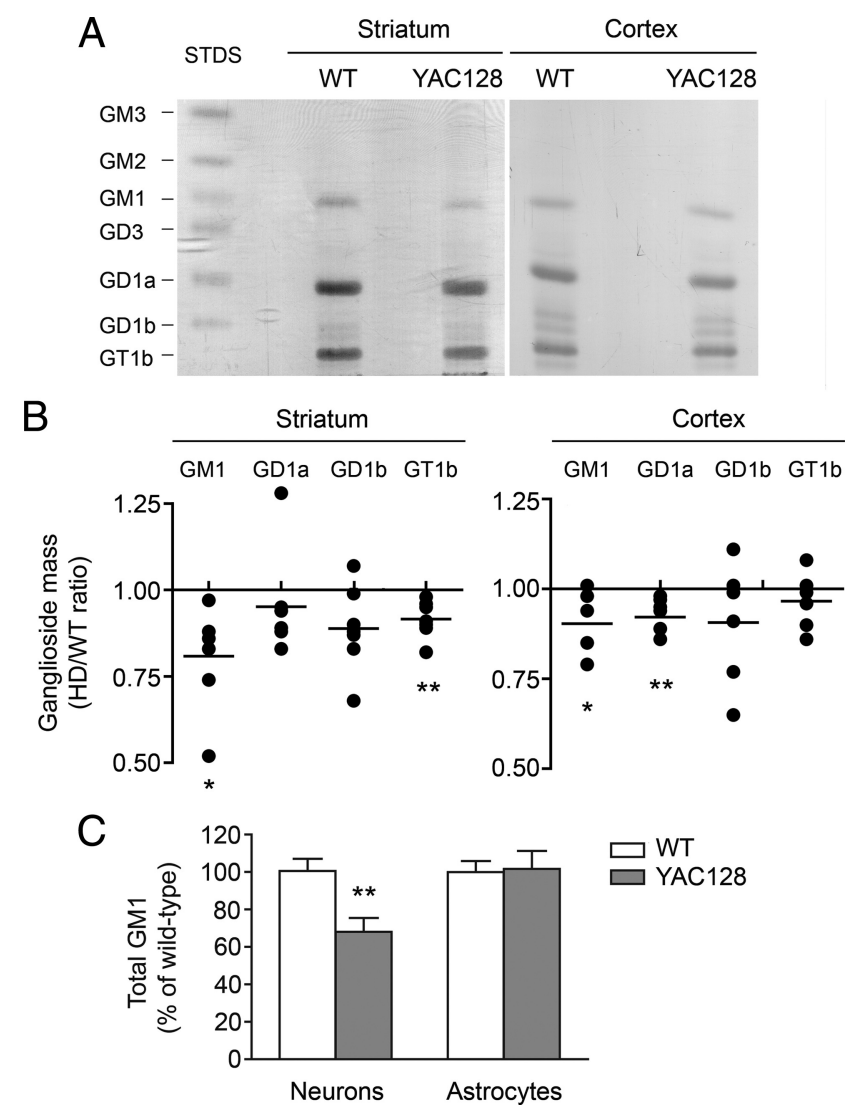

Figure 3. GM1 is reduced in striatum, cortex, and neurons of YAC128 mice. $A$, Representative TLC analysis of striatal and cortical gangliosides. Ganglioside standards (STDS) are indicated. $B$, Densitometric analysis of individual gangliosides extracted from brain regions of six YAC128 mice, separated by TLC and compared with six wild-type littermates. Each dot represents one individual YAC128 mouse. Data are expressed as ratios of HD to wild-type control. C, Total GM1 levels in primary cultures of neurons and astrocytes were measured by dot-blotting with HRPconjugated cholera toxin B. Individual neural cultures from 12 YAC128 newborn mice and 12 wild-type littermates were analyzed. Astrocyte cultures from 16 YAC128 and 18 wild-type littermates were used. Data are expressed as the mean percentage of the average of wild-type values \pm SD. ${ }^{*} p<0.05 ;{ }^{* *} p<0.001$.

inhibitors were administered to the cells $2 \mathrm{~h}$ before induction of apoptosis and administration of GM1.

Htt immunoprecipitation and immunoblotting. After preincubation for $5 \mathrm{~h}$ at $33^{\circ} \mathrm{C}$ in serum-free medium, cells were treated with $50 \mu \mathrm{M}$ GM1 


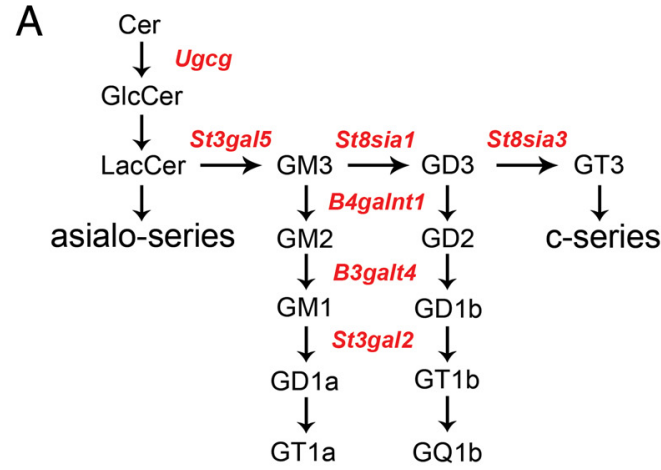

a-series b-series

$\mathrm{B}$
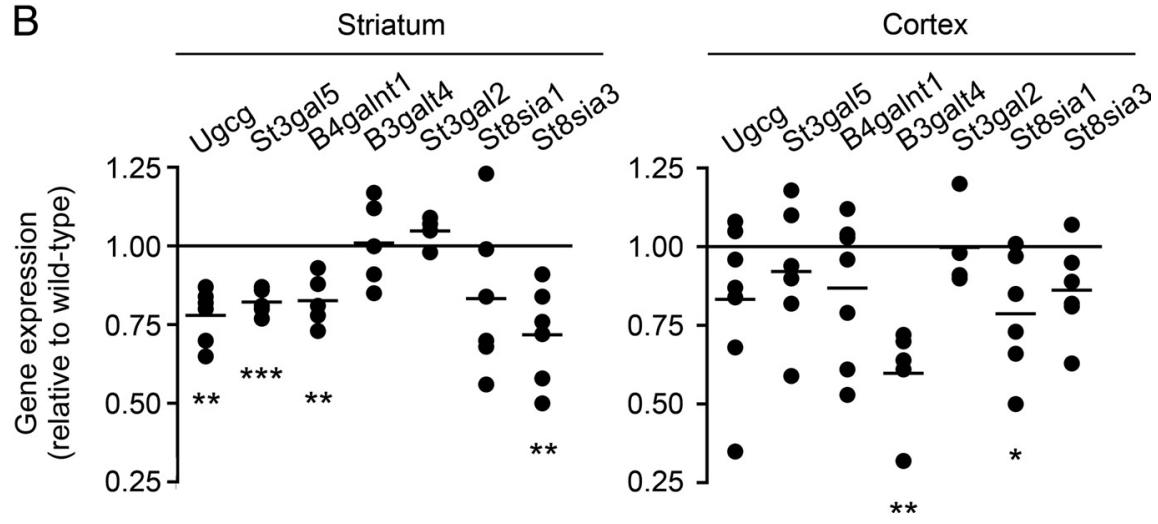

Figure 4. Specific enzymes of the ganglioside biosynthetic pathway are downregulated in striatum and cortex of YAC128 mice. $\boldsymbol{A}$, Simplified scheme of the ganglioside biosynthetic pathway. Critical enzymes in the pathway are indicated in red. Gangliosides of the asialo-series and of the $\boldsymbol{C}$-series are less abundant and were omitted to improve clarity. $\boldsymbol{B}$, Analysis of gene expression in YAC128 mice by real-time PCR. Each dot represents an individual animal. From five to six animals were used in the analysis. Lines indicate the mean value in each group. Data are expressed as ratios of HD to wild type. ${ }^{*} p<0.05 ;{ }^{* *} p<0.001$; ${ }^{* * *} p<0.0001$.

(Alexis) for $5 \mathrm{~min}$ and lysed with RIPA buffer (20 mu Tris, $\mathrm{pH} 8.0,150$ mм NaCl, $1 \%$ Triton X-100, 0.5\% Na-deoxycholate, 0.1\% SDS, $1 \mathrm{~mm}$ EDTA) containing protease inhibitor mixture (1:100, Sigma) and phosphatase inhibitors ( $10 \mathrm{~mm} \mathrm{NaF}, 1 \mathrm{~mm} \mathrm{Na}_{3} \mathrm{VO}_{4}$ ). Immunoprecipitation was performed using monoclonal anti-Htt antibodies (mab2166 and mab2168, Millipore Bioscience Research Reagents) complexed to protein G-Sepharose (Zymed, Invitrogen). The immunoprecipitated protein was resolved on 6\% SDS-PAGE and detected by immunoblotting with anti-Htt (mab2166, 1:5000, Millipore Bioscience Research Reagents) and anti-phosphoSer (1C8, 1:200, Santa Cruz Biotechnology) antibodies. For analysis of AKT, activation cells were lysed in $10 \mathrm{~mm}$ Tris-HCl, pH 7.4, containing 1\% NP40, $10 \mathrm{~mm} \mathrm{NaF}, 1 \mathrm{~mm}$ $\mathrm{Na}_{2} \mathrm{V0}_{4}$, and 1:100 protease inhibitor mixture (Sigma-Aldrich). Proteins were resolved on 10\% SDS-PAGE and immunoblotted with antiphospho-AKT (Ser473) (1:500) or anti-AKT (1:500) (both from Cell Signaling Technology). HRP-conjugated secondary antibodies were used at 1:3000 dilution (Bio-Rad Laboratories). Protein bands were detected by ECL Plus and quantitated with Quantity One software (Bio-Rad Laboratories).

Statistical analysis. Statistical significance was calculated by two-tailed $t$ test and by the ANOVA/Dunnet test (for the data generated in fibroblasts from patients), using Prism 4.0 software (GraphPad Software).

\section{Results}

\section{Striatal HD cells and human skin fibroblasts isolated from} HD patients have decreased GM1 content

We used two striatal cell models of HD: knock-in cells, in which the expression of physiological levels of either wild-type $\left(\mathrm{STH} d h^{7 / 7}\right)$ or mutant Htt (STHdh ${ }^{111 / 111}$ ) is controlled by the endogenous mouse $\mathrm{Hd}$ promoter (Trettel et al., 2000); and immortalized rat striatal cells expressing endogenous wild-type $\mathrm{Htt}$
(ST14A) or overexpressing an N-terminal fragment of mHtt (N548-120Q) (Rigamonti et al., 2000). Knock-in STHdh ${ }^{111 /}$ 111 cells contained 25\% less ganglioside GM1 at the plasma membrane than STHdh $h^{7 / 7}$ cells (Fig. $1 A$ ), as detected by binding of cholera toxin $\mathrm{B}$, a protein that specifically recognizes GM1 (Holmgren et al., 1975). Levels of this ganglioside were further decreased in N548-120Q cells compared with parental ST14A (Fig. $1 A, B)$. Similarly, the total cellular amount of GM1 was decreased in both HD cell models (Fig. 1C), suggesting that synthesis of the ganglioside, rather than its transport from the Golgi to the plasma membrane (Tettamanti, 2004), might be affected in HD cells. To confirm these data, we analyzed cell GM1 content by lipid extraction and ganglioside separation by TLC. Results were virtually identical to those generated using cholera toxin B (Fig. 1D). Importantly, plasma membrane levels of GM1 were also lower in primary fibroblasts derived from HD patients, compared with age-matched controls (Fig. $1 E$; for patients' statistics, see supplemental Table 1, available at www. jneurosci.org as supplemental material).

Expression of B3galt4, the gene encoding GM1/GD1b/GT1c synthase, was significantly downregulated in mutant knock-in, N548-128Q cells (Fig. 2A) and in human HD fibroblasts (Fig. 2B) compared with controls. These data suggest that decreased ganglioside levels in HD cells are due to reduced biosynthesis.

\section{Mutant huntingtin affects ganglioside metabolism in the brain of HD mice}

In agreement with the data obtained in cell lines, analysis of gangliosides extracted from 6-month-old YAC128 mice, a wellcharacterized transgenic model of HD (Slow et al., 2003), showed that GM1 levels were reduced in both striatum and cortex, the most affected brain areas in HD (Fig. $3 A, B$ ). Two other major brain gangliosides, GDla and GT1b (Fig. 3B), were significantly decreased in YAC128 cortex and striatum, respectively. Dot-blot analysis with cholera toxin B revealed that GM1 content was further decreased in primary cultures of YAC128 neurons ( $-32 \%$ compared with wild type), while no deficit was detectable in cultures of YAC128 astrocytes (Fig. 3C). Since astrocytes also express $\mathrm{mHtt}$ (Singhrao et al., 1998), these data suggest that $\mathrm{mHtt}$ affects ganglioside metabolism in a cell-specific manner, and that the small GM1 deficit measured in brain tissue analyzed in toto might actually reflect larger changes at the cellular level.

In line with the biochemical data, the expression of genes encoding enzymes in the ganglioside synthetic pathway (Fig. $4 A$ ), specifically $U g c g$, St3gal5 (also known as GM3 synthase), B4galnt1 (GM2/GD2 synthase), St8sia1 (GD3 synthase), and St8sia3 (GT3 synthase), were significantly downregulated in YAC128 mice compared with wild-type littermates (Fig. 4B). Expression of GM1 synthase (B3galt4) was significantly decreased in the YAC128 cortex, but not in the striatum. However, down- 

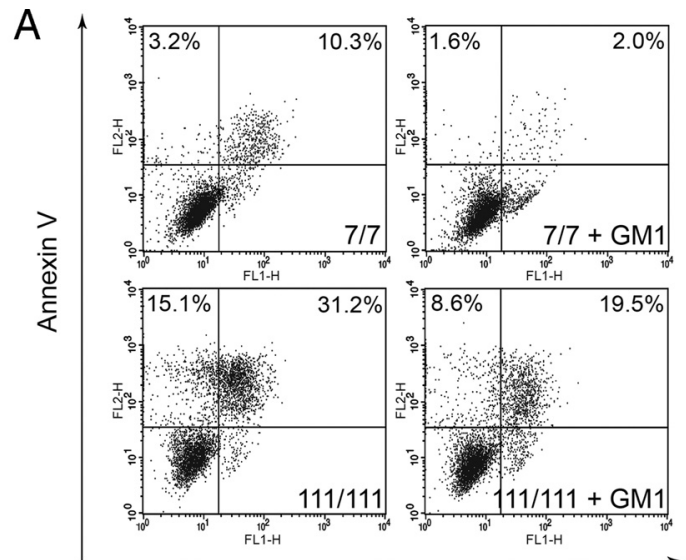

Active caspase-3
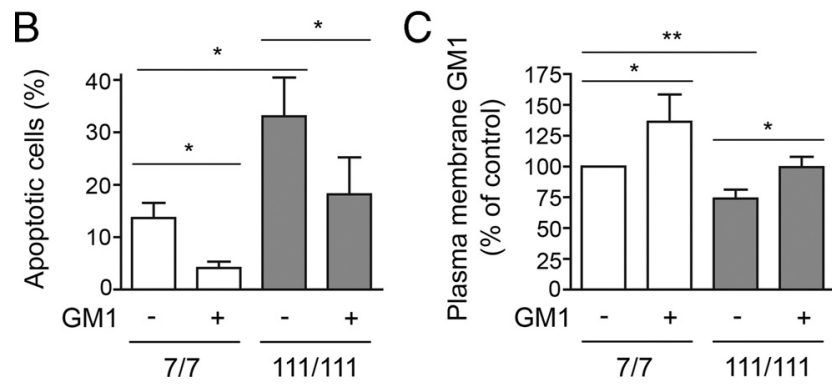

Figure 5. GM1 administration raises plasma membrane ganglioside levels and protects cells from apoptosis. Cells were incubated with or without $50 \mu \mathrm{M} \mathrm{GM1}$ and exposed to apoptotic conditions (serum deprivation at $39^{\circ} \mathrm{C}$ ). $\boldsymbol{A}$, Representative FACS profile of cells after $12 \mathrm{~h}$ incubation in apoptotic conditions. Cells were labeled with Annexin $V$ and then stained for active caspase-3. FL1-H and FL2-H indicate fluorescence intensity for active caspase-3 and annexin V staining, respectively. Double-positive cells in the upper right quadrant are apoptotic cells. Annexin V-positive cells, but active caspase 3-negative cells (upper left quadrant) are early apoptotic cells. The number reported in each quadrant represents the percentage of cells in the quadrant. $B$, Quantitation of apoptotic cells by FACS analysis of annexin V binding. Data are the mean $\pm S D$ of four experiments, each performed in triplicate. $C$, Plasma membrane GM1 levels were measured after GM1 administration by analysis of cholera toxin B binding. Data are expressed as the percentage of control (wild type in basal conditions) and represent the mean \pm SD of three experiments, each performed in triplicate. $7 / 7$, STHdh ${ }^{7 / 7} ; 111 / 111$, STHdh ${ }^{111 / 111}$; ${ }^{*} p<0.05 ;{ }^{* *} p<0.001$.

regulation of upstream enzymes in the pathway may well explain the overall reduced GM1 mass in the striatum of YAC128 mice. No gene expression changes were detected in the hippocampus, a brain area that is less affected in HD (supplemental Fig. $1 \mathrm{~A}$, available at www.jneurosci.org as supplemental material). Normal gene expression and GM1 levels were observed in the spleen of YAC128 mice (supplemental Fig. $1 B, C$, available at www. jneurosci.org as supplemental material).

\section{Administration of GM1 to HD cells restores ganglioside levels and protects cells from apoptosis}

Since plasma membrane GM1 can modulate cell signaling, we reasoned that reduced levels of this ganglioside might alter the response of $\mathrm{HD}$ cells to extracellular stimuli and stress conditions, and affect their susceptibility to apoptosis. If this hypothesis is correct, restoring normal GM1 levels should normalize HD response to stress. To test this hypothesis, we used striatal knock-in cell lines, since these cells are a precise genetic model of $\mathrm{HD}$ without the caveats potentially associated to transgene overexpression. HD cells (knock-in STHdh ${ }^{111 / 111}$ ) were more prone to undergo apoptosis than wild-type cells $\left(\mathrm{STH} H \mathrm{~h}^{7 / 7}\right.$ ) when grown in the absence of serum, and showed increased levels of
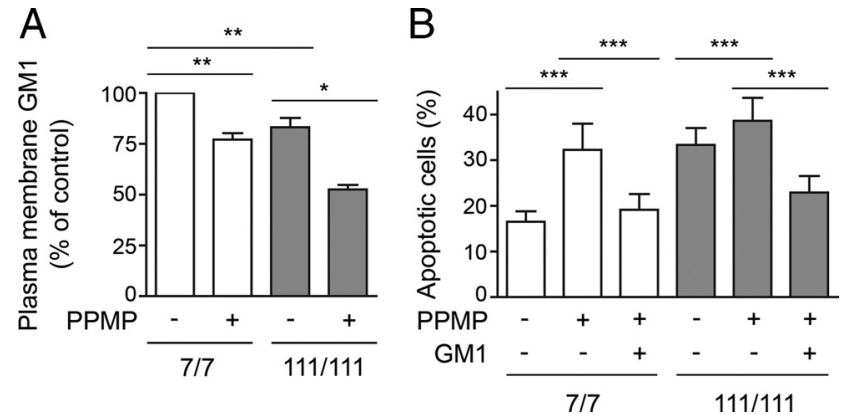

Figure 6. Inhibition of GM1 biosynthesis renders wild-type cells more susceptible to apoptosis. Cells were treated with $10 \mu \mathrm{M}$ PPMP, an inhibitor of the ganglioside biosynthetic pathway, for $3 \mathrm{~d}$ and then exposed to apoptotic conditions (serum deprivation at $39^{\circ} \mathrm{C}$ ). $\boldsymbol{A}$, Plasma membrane levels of GM1 were measured by cholera toxin B-binding and FACS analysis after incubation with PPMP. $\boldsymbol{B}$, The percentage of apoptotic cells on incubation of the cells for $12 \mathrm{~h}$ in serum-free medium was measured by annexin V binding. Data are the mean \pm SD of three experiments. 7/7, STHdh ${ }^{7 / 7} ; 111 / 111$, STHdh ${ }^{111 / 111}$; ${ }^{*} p<0.05$; ${ }^{* *} p<0.001$; ${ }^{* * *} p<0.0001$.

active caspase-3 and increased annexin $\mathrm{V}$ binding, an early marker of apoptosis (Fig. 5A). Administration of GM1 protected both wild-type and HD cells from apoptosis in a dose-dependent manner (supplemental Fig. $2 \mathrm{~A}$, available at www.jneurosci.org as supplemental material). Importantly, GM1 (50 $\mu \mathrm{M})$ restored normal susceptibility to apoptosis in HD cells, which, on treatment with the ganglioside, became indistinguishable from control wild-type cells (Fig. 5B). Protection from apoptosis in $\mathrm{HD}$ cells occurred in parallel to complete restoration of GM1 levels on ganglioside administration (Fig. 5C; supplemental Fig. $2 B$, available at www.jneurosci.org as supplemental material). At a GM1 concentration $(10 \mu \mathrm{M})$ that did not restore cell ganglioside levels, neuroprotection was not achieved (supplemental Fig. $2 A, B$, available at www.jneurosci.org as supplemental material). In treated wild-type cells, where the incorporation of exogenous GM1 resulted in a further increase of GM1 content above their normal levels, cell survival was also further augmented. These results support our hypothesis that GM1 modulates cell response to stress and that decreased GM1 content in HD cells contributes to their heightened susceptibility to apoptosis.

\section{Inhibition of ganglioside biosynthesis in wild-type cells increases cell susceptibility to apoptosis and recapitulates STHdh ${ }^{111 / 111}$ cell phenotype}

To further corroborate our hypothesis linking GM1 levels and susceptibility to apoptosis in HD cells, we inhibited GM1 synthesis in wild-type STHdh ${ }^{7 / 7}$ cells to reduce GM1 levels to the amount observed in STHdh $h^{111 / 111}$ cells (Fig. 6A). This was achieved by incubating wild-type cells for $3 \mathrm{~d}$ with $10 \mu \mathrm{M}$ PPMP, a well-known inhibitor of glucosylceramide synthase (Ugcg), the enzyme that catalyzes the first reaction committed to ganglioside biosynthesis. Remarkably, PPMP treatment increased STHdh ${ }^{7 / 7}$ cell susceptibility to apoptosis to the levels observed in STHdh ${ }^{111 /}$ 111 cells (Fig. 6B). Administration of GM1 abolished PPMP effects, suggesting that the increased susceptibility to apoptosis was determined by decreased levels of GM1, rather than to the accumulation of metabolic precursors such as ceramide or decreased synthesis of other gangliosides in the pathway. These data confirm that even a small reduction in ganglioside synthesis is sufficient to sensitize cells to stress.

GM1 promotes AKT activation and $\mathrm{mHtt}$ phosphorylation We next asked whether the prosurvival action of GM1 was mediated by AKT activation, since the PI3K/AKT pathway is one of the 
A
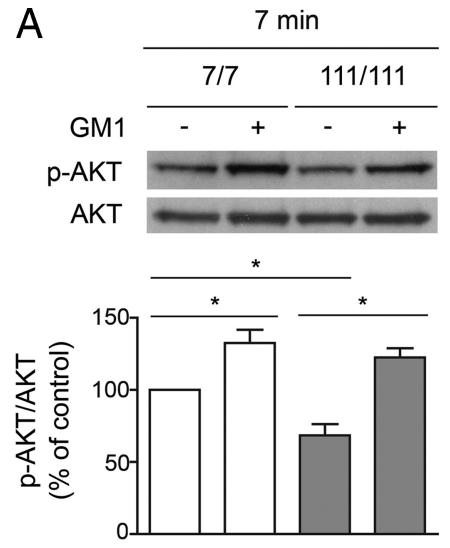

B

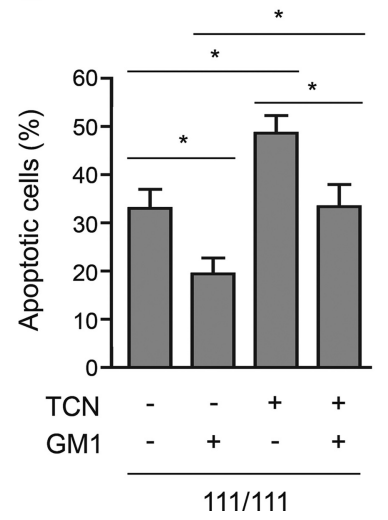

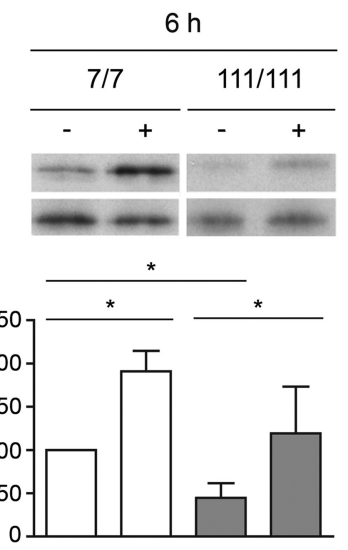

C
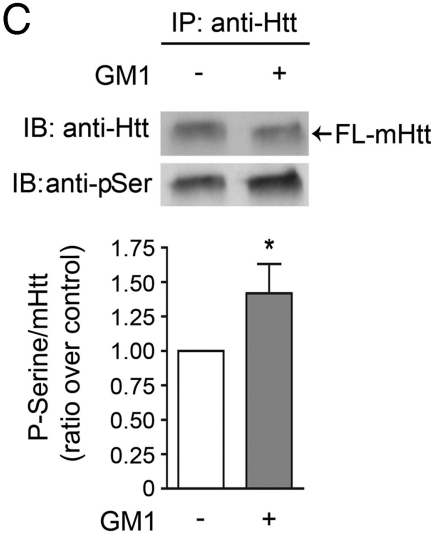

Figure 7. Administration of GM1 results in AKT activation and increased $\mathrm{mHtt}$ phosphorylation. $\boldsymbol{A}$, Akt phosphorylation was measured $7 \mathrm{~min}$ and $6 \mathrm{~h}$ after addition of GM1 in serum-free medium and incubation at $39^{\circ} \mathrm{C}$ to induce cell death. Analysis of phospho-AKT/AKT ratio, indicative of AKT activation, was performed by densitometric analysis of immunoblots in three independent experiments. In each experiment, the phospho-AKT/AKT ratio measured in wildtype untreated cells (control) was arbitrarily set to $100 \%$, to which HD and GM1-treated samples were compared. Mean values \pm SD and representative immunoblots are shown. $\boldsymbol{B}$, Cells were preincubated for $2 \mathrm{~h}$ with $1 \mu \mathrm{M}$ TCN, an inhibitor of AKT activation, before GM1 administration and exposure to apoptotic stress (serum-free medium at $39^{\circ} \mathrm{C}$ ). The percentage of apoptotic cells was measured by annexin V binding. Data are the mean \pm SD of three experiments, each performed in triplicate. C, STHdh ${ }^{111 / 111}$ cells were incubated with or without GM1 for 5 min. Mutant Htt was immunoprecipitated and its phosphorylation state was assessed by immunoblotting with anti-pSer (phospho-Ser) antibody. A representative immunoblot is shown, along with the densitometric analysis performed on four independent experiments. In each experiment, the ratio $\mathrm{p}$-Ser/mHtt measured in untreated cells was arbitrarily set to 1, and the ratio obtained for GM1-treated cells was compared with it. Statistical significance was determined by two-tailed $t$ test. 7/7, STHdh ${ }^{7 / 7} ; 111 / 111$, STHdh ${ }^{111 / 111} ;$ FL-mHtt, full-length $\mathrm{mHtt}^{*}{ }^{*} \mathrm{p}<0.05$.

most important pathways contributing to neural survival (Kaplan and Miller, 2000). In basal conditions, STHdh $h^{111 / 111}$ cells had a lower phospho-AKT/AKT ratio than wild-type cells (Fig. 7A). GM1 administration increased the phospho-AKT/AKT ratio, both in STHdh $h^{7 / 7}$ and in STHdh ${ }^{111 / 111}$ cells, an effect that was still measurable $6 \mathrm{~h}$ after the application of apoptotic stress. Notably, after GM1 administration, levels of active (phospho) AKT in STHdh ${ }^{111 / 111}$ were restored to normal (Fig. $7 A$ ). To further investigate the involvement of AKT in GM1mediated neuroprotection, we preincubated STHdh ${ }^{111 / 111}$ cells with TCN, an inhibitor of AKT activation, before induction of apoptosis and treatment with GM1. TCN blocked the antiapoptotic effect of GM1 only partly (Fig. 7B), suggesting that the neuroprotective action of GM1 is only partially dependent on AKT

activation and that other prosurvival effects must be at play. In the presence of K252a, a pan-trk receptor inhibitor, GM1 protective activity was still fully preserved, indicating that the Trk receptor pathway, which is activated by GM1 in other models (Mocchetti, 2005), is not involved in our experimental conditions (supplemental Fig. 3, available at www.jneurosci.org as supplemental material). In some model of excitotoxicity and neurotoxicity, intracellular GM1 and its semisynthetic analog LIGA-20 exert neuroprotection by directly modulating the activity of the nuclear $\mathrm{Na} / \mathrm{Ca}$ exchanger in the nuclear membrane and $\mathrm{Ca}^{2+}$ homeostasis (Ledeen and $\mathrm{Wu}, 2008$ ). However, such a protective mechanism is not likely to be at play in our experimental model, as LIGA-20, which had been shown to be at least an order of magnitude more potent than GM1 (Wu et al., 2004), was not effective in protecting striatal cells in our study (supplemental Fig. 4, available at www.jneurosci.org as supplemental material).

Since activation of AKT may result in $\mathrm{mHtt}$ phosphorylation and reduction of its toxicity, we analyzed the phosphorylation state of mHtt on cell treatment with GM1. As shown in Figure $7 C$, administration of GM1 to STHdh ${ }^{111 / 111}$ cells resulted in increased mHtt phosphorylation as assessed by $\mathrm{mHtt}$ immunoprecipitation and immunoblotting with an anti phosphoSer antibody.

\section{Discussion}

Despite being a monogenic disease, HD is a complex disorder resulting from a cascade of pathogenic events triggered by $\mathrm{mHtt}$. Thus, one of the major challenges in the field is to discriminate between mere epiphenomena and dysfunctions that contribute to disease pathogenesis and progression. Here, we show that ganglioside GM1 levels are reduced in HD cells. Gangliosides have a plethora of functions in the brain (Mocchetti, 2005). GM1, in particular, is involved in signaling (Prinetti et al., 2009), neurite outgrowth (Ichikawa et al., 2009), and neurotransmission (Furuse et al., 1998). Therefore, even a partial reduction of GM1 is likely to have a profound impact on the physiology of HD neurons. GM2/GD2 synthase null mice develop motor symptoms that are common to YAC128 HD mice, including hindlimb clasping, impaired rotarod performance, reduced open field activity, and catalepsy (Chiavegatto et al., 2000; Slow et al., 2003). In these mice, axonal degeneration and demyelination in the CNS and in the sciatic nerve precede motor problems by several months (Sheikh et al., 1999; Chiavegatto et al., 2000), a phenotype that is reminiscent of the early white matter dysfunction observed in presymptomatic HD patients (Ciarmiello et al., 2006) and R6/2 HD mice (Wade et al., 2008). Similarly to HD mouse models, GM2/GD2 synthase null mice are also more susceptible to excitotoxic stimuli (Wu et al., 2005). Motor problems are already present in heterozygous GM2/GD2 synthase ${ }^{+/-}$mice (Chiavegatto et al., 2000), indicating that even a partial reduction of complex gangliosides is sufficient to induce neural dysfunction and neurodegeneration.

In our study, we found that plasma membrane and total levels of GM1 were significantly reduced in HD cells, in YAC128 striatum and cortex, and in derived primary neurons. GM1 levels were lower in immortalized striatal cells expressing an N-terminal fragment of mHtt (N548-120Q) than in knock-in cells expressing endogenous levels of the full-length protein $\left(\mathrm{STH} H h^{111 / 111}\right)$, a finding that is consistent with a considerable body of evidence demonstrating that cleavage products of $\mathrm{mHtt}$ are more toxic 
than the full-length protein. GT1b and GD1a were also decreased in the striatum and cortex of YAC128 mice. GD1a serves as a reserve for the spatially regulated generation of GM1 by the sialidase Neu3 in various neural compartments (Tettamanti et al., 1972; Da Silva et al., 2005). Since both GT1b and GD1a are ligands for the myelin-associated glycoprotein and play a role in myelin-axon adhesion and axon stability (Abad-Rodriguez and Robotti, 2007), their deficit in HD is also likely to affect brain functions.

Our analysis was performed in 6-month-old mice, when animals were symptomatic but did not yet show signs of neurodegeneration (Slow et al., 2003). Therefore, the ganglioside profile herein described reflects the activity of metabolic pathways, rather than the accumulation of reactive glia, loss of neurons, or other factors that could potentially confound data interpretation. Reduced synthesis likely accounts for the observed decrease of specific gangliosides, as indicated by downregulated B3galt4 (GM1/GD1b/GT1c synthase) expression in striatal cells and in human HD fibroblasts. The expression of other genes involved in the ganglioside biosynthetic pathway was also decreased in cortex and striatum of YAC128 mice, compared with wild-type littermates, but not in the hippocampus. Whether aberrant ganglioside metabolism contributes to the region-specific neural dysfunction typical of the HD pathology remains to be elucidated. Expression of the ganglioside biosynthetic enzymes is highly regulated in a cell- and tissue-specific manner (Yu et al., 2004). Overall, the repressive effect exerted by $\mathrm{mHtt}$ might arise from its action on the transcription factor $S p 1$, which is involved in the transcription of most of the affected ganglioside biosynthetic genes (Yu et al., 2004), or on the cAMP response elementbinding protein (CREB), which regulates transcription of the B3galt4 gene. Indeed, the activity of both Sp1 and CREB has been shown to be impaired in several HD models (Imarisio et al., 2008). Transcriptional dysregulation in HD is cell and tissue context dependent (Dunah et al., 2002; Cornett et al., 2006; Qiu et al., 2006), thus potentially explaining why, in our study, the ganglioside biosynthetic genes were found to be differentially affected in various brain regions and peripheral cells.

Reduced activity of the ganglioside biosynthetic pathway and reduced GM1 levels were recently reported in the striatum of R6/1 transgenic mice (Desplats et al., 2007), which express an $\mathrm{N}$-terminal fragment of mHtt (Mangiarini et al., 1996). In that study, three human HD brains were also analyzed, but no conclusive results were reached concerning levels of GM1, probably due to the small number of samples analyzed and to the fact that they were derived from HD patients with $>80 \%$ loss of striatal neurons (Desplats et al., 2007).

Our study demonstrates that GM1 is decreased in human skin fibroblasts derived from HD patients. Other pathways that contribute to HD pathology are also affected peripherally, where cell-autonomous or systemic compensatory mechanisms may help HD cells to cope with the dysfunction. The possibility of measuring a specific HD-related dysfunction in peripheral cells might have important applications in the field of disease biomarkers. In this regard, it is worth mentioning that one of the human fibroblast lines used in this study $\left(\mathrm{HD}_{50}\right)$ was derived from an 11-year-old asymptomatic boy who developed the disease 15 years later (data from Coriell Cell Repositories, Camden, NJ). Hence, aberrant ganglioside metabolism was already manifested in peripheral tissues before clinical disease onset.

The most crucial finding in our study is that even relatively small variations in the amount of plasma membrane GM1 may result in dramatic changes in HD cell susceptibility to apoptosis, and that administration of exogenous GM1 can restore ganglioside levels and cell survival. Importantly, we were able to reproduce the HD phenotype (in terms of susceptibility to apoptosis) in wild-type cells by pharmacologically reducing cellular GM1 content to the levels observed in HD cells. These data strongly suggest that reduced amounts of GM1 in HD cells are causative of cell dysfunction, rather than an epiphenomenon.

Administration of GM1 to striatal cells resulted in the activation of the prosurvival kinase AKT. This is particularly important in the context of HD where the PI3K/AKT pathway is impaired (Humbert et al., 2002; Song et al., 2002; Colin et al., 2005). In our model, GM1 treatment abolished the difference in the phosphoAKT/AKT ratio between wild-type and HD cells. Another remarkable phenomenon triggered by GM1 administration was the increase in $\mathrm{mHtt}$ phosphorylation. Because phospho-mHtt was detected with an anti-pSer antibody after Htt immunoprecipitation, it was not possible to establish which kinase/s might be responsible for the phosphorylation of $\mathrm{mHtt}$ and at which site. A likely candidate is AKT itself, which has been shown to attenuate $\mathrm{mHtt}$ toxicity by phosphorylating the protein (Humbert et al., 2002; Zala et al., 2008; Warby et al., 2009). Other kinases could also be potentially activated by GM1 leading to Htt phosphorylation at different sites. Although it remains to be investigated whether mHtt phosphorylation was directly responsible for the neuroprotective action of GM1 in our model, previous studies have shown that phosphorylation of $\mathrm{mHtt}$ by various kinases invariably results in decreased protein toxicity (Imarisio et al., 2008). Phosphorylation of $\mathrm{mHtt}$ has been reported to decrease its fragmentation (Luo et al., 2005; Schilling et al., 2006; Imarisio et al., 2008; Warby et al., 2009) and nuclear accumulation (Warby et al., 2009). In addition, phosphorylation of $\mathrm{mHtt}$ at $\mathrm{S} 421$ by AKT restores axonal transport and BDNF release (Zala et al., 2008), both of which are impaired in HD. The neuroprotective effect of GM1 in our model was only partially dependent on AKT activation. In fact, an AKT inhibitor reduced GM1 protection, but did not abolish it. Therefore, GM1 might have activated an additional prosurvival pathway or, alternatively, blocked a proapoptotic step. Increased $\mathrm{mHtt}$ phosphorylation by kinases other than AKT could also explain the additional AKTindependent protection.

Our study opens the door to a novel potential therapeutic intervention in HD. Exogenous administration of ganglioside GM1 or its synthetic derivatives has shown neuroprotective properties in models of neural injury by growth factor withdrawal (Ferrari et al., 1995) or excitotoxicity (Wu et al., 2004), as well as in primate models of Parkinson's disease (Pope-Coleman et al., 2000) and in stroke (Oppenheimer, 1990). In HD, where endogenous levels of the ganglioside are reduced, GM1 is likely to have multiple beneficial effects, by restoring normal ganglioside content and by targeting multiple aspects of the HD pathology: from cell signaling and AKT activation to $\mathrm{mHtt}$ phosphorylation, susceptibility to apoptosis, and potentially also axonal transport and neurotrophin release and excitotoxicity. Importantly, previous clinical trials that have tested the effects of GM1 in patients with stroke (Alter, 1998), Parkinson's disease (Schneider, 1998), and spinal cord injury (Chinnock and Roberts, 2005) have shown that the compound is relatively safe to use. Possible potential adverse effects, such as the development of a peripheral neuropathy known as Guillain-Barré 
syndrome are rare (Alter, 1998) and the risk/benefit ratio might be acceptable in the case of HD.

\section{References}

Abad-Rodriguez J, Robotti A (2007) Regulation of axonal development by plasma membrane gangliosides. J Neurochem 103 [Suppl 1]: $47-55$.

Alter M (1998) GM1 ganglioside for acute ischemic stroke. Trial design issues. Ann N Y Acad Sci 845:391-401.

Bae BI, Xu H, Igarashi S, Fujimuro M, Agrawal N, Taya Y, Hayward SD, Moran TH, Montell C, Ross CA, Snyder SH, Sawa A (2005) p53 mediates cellular dysfunction and behavioral abnormalities in Huntington's disease. Neuron 47:29-41.

Chiavegatto S, Sun J, Nelson RJ, Schnaar RL (2000) A functional role for complex gangliosides: motor deficits in GM2/GD2 synthase knockout mice. Exp Neurol 166:227-234.

Chinnock P, Roberts I (2005) Gangliosides for acute spinal cord injury. Cochrane Database Syst Rev 2:CD004444.

Ciarmiello A, Cannella M, Lastoria S, Simonelli M, Frati L, Rubinsztein DC, Squitieri F (2006) Brain white-matter volume loss and glucose hypometabolism precede the clinical symptoms of Huntington's disease. J Nucl Med 47:215-222.

Clarke G, Collins RA, Leavitt BR, Andrews DF, Hayden MR, Lumsden CJ, McInnes RR (2000) A one-hit model of cell death in inherited neuronal degenerations. Nature 406:195-199.

Colin E, Régulier E, Perrin V, Dürr A, Brice A, Aebischer P, Déglon N, Humbert S, Saudou F (2005) Akt is altered in an animal model of Huntington's disease and in patients. Eur J Neurosci 21:1478-1488.

Cornett J, Smith L, Friedman M, Shin JY, Li XJ, Li SH (2006) Contextdependent dysregulation of transcription by mutant huntingtin. J Biol Chem 281:36198-36204.

Da Silva JS, Hasegawa T, Miyagi T, Dotti CG, Abad-Rodriguez J (2005) Asymmetric membrane ganglioside sialidase activity specifies axonal fate. Nat Neurosci 8:606-615.

Desplats PA, Denny CA, Kass KE, Gilmartin T, Head SR, Sutcliffe JG, Seyfried TN, Thomas EA (2007) Glycolipid and ganglioside metabolism imbalances in Huntington's disease. Neurobiol Dis 27:265-277.

Dunah AW, Jeong H, Griffin A, Kim YM, Standaert DG, Hersch SM, Mouradian MM, Young AB, Tanese N, Krainc D (2002) Sp1 and TAFII130 transcriptional activity disrupted in early Huntington's disease. Science 296:2238-2243.

Ferrari G, Anderson BL, Stephens RM, Kaplan DR, Greene LA (1995) Prevention of apoptotic neuronal death by GM1 ganglioside. Involvement of Trk neurotrophin receptors. J Biol Chem 270:3074-3080.

Furuse H, Waki H, Kaneko K, Fujii S, Miura M, Sasaki H, Ito KI, Kato H, Ando S (1998) Effect of the mono- and tetra-sialogangliosides, GM1 and GQ1b, on long-term potentiation in the CA1 hippocampal neurons of the guinea pig. Exp Brain Res 123:307-314.

Hakomori Si SI (2002) Inaugural article: the glycosynapse. Proc Natl Acad Sci U S A 99:225-232.

Holmgren J, Lönnroth I, Månsson J, Svennerholm L (1975) Interaction of cholera toxin and membrane GM1 ganglioside of small intestine. Proc Natl Acad Sci U S A 72:2520-2524.

Humbert S, Bryson EA, Cordelières FP, Connors NC, Datta SR, Finkbeiner S, Greenberg ME, Saudou F (2002) The IGF-1/Akt pathway is neuroprotective in Huntington's disease and involves Huntingtin phosphorylation by Akt. Dev Cell 2:831-837.

Ichikawa N, Iwabuchi K, Kurihara H, Ishii K, Kobayashi T, Sasaki T, Hattori N, Mizuno Y, Hozumi K, Yamada Y, Arikawa-Hirasawa E (2009) Binding of laminin-1 to monosialoganglioside GM1 in lipid rafts is crucial for neurite outgrowth. J Cell Sci 122:289-299.

Imarisio S, Carmichael J, Korolchuk V, Chen CW, Saiki S, Rose C, Krishna G, Davies JE, Ttofi E, Underwood BR, Rubinsztein DC (2008) Huntington's disease: from pathology and genetics to potential therapies. Biochem J 412:191-209.

Kaplan DR, Miller FD (2000) Neurotrophin signal transduction in the nervous system. Curr Opin Neurobiol 10:381-391.

Karten B, Hayashi H, Francis GA, Campenot RB, Vance DE, Vance JE (2005) Generation and function of astroglial lipoproteins from Niemann-Pick type C1-deficient mice. Biochem J 387:779-788.
Ladisch S, Gillard B (1985) A solvent partition method for microscale ganglioside purification. Anal Biochem 146:220-231.

Ledeen RW, Wu G (2008) Nuclear sphingolipids: metabolism and signaling. J Lipid Res 49:1176-1186.

Luo S, Vacher C, Davies JE, Rubinsztein DC (2005) Cdk5 phosphorylation of huntingtin reduces its cleavage by caspases: implications for mutant huntingtin toxicity. J Cell Biol 169:647-656.

Mangiarini L, Sathasivam K, Seller M, Cozens B, Harper A, Hetherington C, Lawton M, Trottier Y, Lehrach H, Davies SW, Bates GP (1996) Exon 1 of the HD gene with an expanded CAG repeat is sufficient to cause a progressive neurological phenotype in transgenic mice. Cell 87:493-506.

Mocchetti I (2005) Exogenous gangliosides, neuronal plasticity and repair, and the neurotrophins. Cell Mol Life Sci 62:2283-2294.

Oppenheimer S (1990) GM1 ganglioside therapy in acute ischemic stroke. Stroke 21:825.

Pope-Coleman A, Tinker JP, Schneider JS (2000) Effects of GM1 ganglioside treatment on pre- and postsynaptic dopaminergic markers in the striatum of parkinsonian monkeys. Synapse 36:120-128.

Prinetti A, Loberto N, Chigorno V, Sonnino S (2009) Glycosphingolipid behaviour in complex membranes. Biochim Biophys Acta 1788:184-193.

Qiu Z, Norflus F, Singh B, Swindell MK, Buzescu R, Bejarano M, Chopra R, Zucker B, Benn CL, DiRocco DP, Cha JH, Ferrante RJ, Hersch SM (2006) Spl is up-regulated in cellular and transgenic models of Huntington disease, and its reduction is neuroprotective. J Biol Chem 281:16672-16680.

Rigamonti D, Bauer JH, De-Fraja C, Conti L, Sipione S, Sciorati C, Clementi E, Hackam A, Hayden MR, Li Y, Cooper JK, Ross CA, Govoni S, Vincenz C, Cattaneo E (2000) Wild-type huntingtin protects from apoptosis upstream of caspase-3. J Neurosci 20:3705-3713.

Schilling B, Gafni J, Torcassi C, Cong X, Row RH, LaFevre-Bernt MA, Cusack MP, Ratovitski T, Hirschhorn R, Ross CA, Gibson BW, Ellerby LM (2006) Huntingtin phosphorylation sites mapped by mass spectrometry. Modulation of cleavage and toxicity. J Biol Chem 281:23686-23697.

Schneider JS (1998) GM1 ganglioside in the treatment of Parkinson's disease. Ann N Y Acad Sci 845:363-373.

Sheikh KA, Sun J, Liu Y, Kawai H, Crawford TO, Proia RL, Griffin JW, Schnaar RL (1999) Mice lacking complex gangliosides develop Wallerian degeneration and myelination defects. Proc Natl Acad Sci U S A 96:7532-7537.

Simpson MA, Cross H, Proukakis C, Priestman DA, Neville DC, Reinkensmeier G, Wang H, Wiznitzer M, Gurtz K, Verganelaki A, Pryde A, Patton MA, Dwek RA, Butters TD, Platt FM, Crosby AH (2004) Infantile-onset symptomatic epilepsy syndrome caused by a homozygous loss-of-function mutation of GM3 synthase. Nat Genet 36:1225-1229.

Singhrao SK, Thomas P, Wood JD, MacMillan JC, Neal JW, Harper PS, Jones AL (1998) Huntingtin protein colocalizes with lesions of neurodegenerative diseases: an investigation in Huntington's, Alzheimer's, and Pick's diseases. Exp Neurol 150:213-222.

Sipione S, Rigamonti D, Valenza M, Zuccato C, Conti L, Pritchard J, Kooperberg C, Olson JM, Cattaneo E (2002) Early transcriptional profiles in huntingtin-inducible striatal cells by microarray analyses. Hum Mol Genet 11:1953-1965.

Slow EJ, van Raamsdonk J, Rogers D, Coleman SH, Graham RK, Deng Y, Oh R, Bissada N, Hossain SM, Yang YZ, Li XJ, Simpson EM, Gutekunst CA, Leavitt BR, Hayden MR (2003) Selective striatal neuronal loss in a YAC128 mouse model of Huntington disease. Hum Mol Genet 12: 1555-1567.

Song C, Perides G, Liu YF (2002) Expression of full-length polyglutamine-expanded Huntingtin disrupts growth factor receptor signaling in rat pheochromocytoma (PC12) cells. J Biol Chem 277:6703-6707.

Sonnino S, Mauri L, Chigorno V, Prinetti A (2007) Gangliosides as components of lipid membrane domains. Glycobiology 17:1R-13R.

Squitieri F, Frati L, Ciarmiello A, Lastoria S, Quarrell O (2006) Juvenile Huntington's disease: does a dosage-effect pathogenic mechanism differ from the classical adult disease? Mech Ageing Dev 127:208-212.

Tettamanti G (2004) Ganglioside/glycosphingolipid turnover: new concepts. Glycoconj J 20:301-317.

Tettamanti G, Morgan IG, Gombos G, Vincendon G, Mandel P (1972) Subsynaptosomal localization of brain particulate neuraminidose. Brain Res 47:515-518.

Trettel F, Rigamonti D, Hilditch-Maguire P, Wheeler VC, Sharp AH, 
Persichetti F, Cattaneo E, MacDonald ME (2000) Dominant phenotypes produced by the HD mutation in STHdh(Q111) striatal cells. Hum Mol Genet 9:2799-2809.

Wade A, Jacobs P, Morton AJ (2008) Atrophy and degeneration in sciatic nerve of presymptomatic mice carrying the Huntington's disease mutation. Brain Res 1188:61-68.

Walker FO (2007) Huntington's disease. Lancet 369:218-228.

Warby SC, Doty CN, Graham RK, Shively J, Singaraja RR, Hayden MR (2009) Phosphorylation of huntingtin reduces the accumulation of its nuclear fragments. Mol Cell Neurosci 40:121-127.

Wu G, Lu ZH, Xie X, Ledeen RW (2004) Susceptibility of cerebellar granule neurons from GM2/GD2 synthase-null mice to apoptosis induced by glutamate excitotoxicity and elevated $\mathrm{KCl}$ : rescue by GM1 and LIGA20. Glycoconj J 21:305-313.

Wu G, Lu ZH, Wang J, Wang Y, Xie X, Meyenhofer MF, Ledeen RW (2005) Enhanced susceptibility to kainate-induced seizures, neuronal apoptosis, and death in mice lacking gangliotetraose gangliosides: protection with LIGA 20, a membrane-permeant analog of GM1. J Neurosci 25:11014-11022.

Yu RK, Bieberich E, Xia T, Zeng G (2004) Regulation of ganglioside biosynthesis in the nervous system. J Lipid Res 45:783-793.

Zala D, Colin E, Rangone H, Liot G, Humbert S, Saudou F (2008) Phosphorylation of mutant huntingtin at $S 421$ restores anterograde and retrograde transport in neurons. Hum Mol Genet 17:3837-3846. 